\title{
$\angle$ Research Square \\ The Comparison of Diagnostic Criteria in Children with Familial Mediterranean Fever
}

Esra Nagehan Akyol Onder ( $\square$ esra.nagehan.7@hotmail.com )

Manisa Celal Bayar Üniversitesi: Manisa Celal Bayar Universitesi https://orcid.org/0000-0003-03212204

\section{Kudret Ebru Özcan}

Istanbul gaziosmanpaşa training and research hospital

\section{Feride Iffet Sahin}

Baskent Universitesi Ankara Hospital: Baskent Universitesi Ankara Hastanesi

\section{Kaan Savas Gulleroglu}

Baskent Universitesi Ankara Hospital: Baskent Universitesi Ankara Hastanesi

\section{Esra Baskin}

Baskent Universitesi Ankara Hospital: Baskent Universitesi Ankara Hastanesi

\section{Research Article}

Keywords: Diagnostic criteria, Familial Mediterranean Fever, pediatric, recurrent polyserositis, TelHashomer criteria

Posted Date: July 23rd, 2021

DOI: https://doi.org/10.21203/rs.3.rs-705764/v1

License: (c) (i) This work is licensed under a Creative Commons Attribution 4.0 International License.

Read Full License 


\section{Abstract}

Familial Mediterranean Fever (FMF) is an autoinflammatory disease characterized with recurrent attacks of fever and serositis. The diagnosis is made according to clinical findings and supported by genetic analysis. The most used adult diagnostic criteria are the Tel-Hashomer criteria. The pediatric criteria for the FMF diagnosis of children were described in 2009, but their efficacy should be supported with further reports. In this study, we planned to compare the pediatric criteria and the Tel-Hashomer criteria in our FMF patients. We also aimed to evaluate the importance of the 2019 Eurofever/PRINTO classification criteria in this patient group. A total of 113 patients diagnosed with FMF were included in our study. Demographic features and laboratory findings were retrospectively recorded from the patients' files. The patients were evaluated with the Tel-Hashomer, pediatric and Eurofever/PRINTO classification criteria. At least two of five new pediatric criteria were as sensitive (88.6\%) and specific (84.62\%) as the TelHashomer criteria (sensitivity $69.9 \%$, specificity $95.7 \%$ ). We also evaluated the Eurofever/PRINTO classification criteria in our patients and found its sensitivity $93.8 \%$ and specificity $90.6 \%$. Conclusion: Using pediatric criteria in the diagnosis of FMF in children is a feasible and simple method that can diagnose the disease based on at least two criteria. Therefore, our study supports the use of pediatric criteria in the diagnosis of FMF in children. Our results also confirm that the Eurofever/PRINTO classification criteria can be successfully used in the diagnosis of FMF due to their high sensitivity (93.8\%) and specificity (90.6\%).

\section{What Is Known?}

- The FMF diagnosis is made according clinical findings and supported by genetic analysis.

- It is difficult to use adult diagnostic criteria in pediatric FMF patients.

What is new?

- Our study supports both the use of pediatric criteria and Eurofever/PRINTO classification criteria in clinical practice.

\section{Introduction}

Familial Mediterranean fever (FMF) is an autosomal recessive illness with relapsing-remitting episodes of fever and serositis [1]. Although most patients are of Mediterranean origin, especially Turkish, Arabian, and Sephardic-Jewish with the carrier frequencies of $1 / 5$, and Armenian with a carrier frequency of $1 / 7$, it is also a global disorder affecting more than 100,000 people around the world [2]. It is the most common periodic fever syndrome and the most frequent Mendelian autoinflammatory disease. It occurs due to recessive mutations in the MEFV gene on chromosome 16p13.3 [3, 4]. The MEFV gene encodes the pyrin protein, which is involved in apoptosis and inflammation. Mutations interfere with the role of the pyrin domain, and an uninterrupted inflammatory cascade begins [3]. 
Although the disease is inherited in an autosomal recessive pattern, patients with a typical FMF phenotype can have a heterozygous mutation of MEFV [5]. The diagnosis remains predominantly clinical because of the variable penetrance of FMF and the high frequency of MEFV carriers in certain regions which could lead to misdiagnosis by using genetic testing alone. Several sets of criteria for adult patients have been suggested but the most widely used criteria remain the classic Tel-Hashomer [6] and the most recent Livneh [7] criteria. There is still no consensus concerning the FMF diagnostic criteria in children. A new set of diagnostic criteria for FMF in pediatric patients was established by Yalcınkaya et al. [8] in 2009. There are some contradictory results in recent validation studies, and therefore these criteria should be supported with further reports. Recently, the Eurofever/PRINTO group validated new evidence-based classification criteria for autoinflammatory recurrent fevers including FMF in pediatric patients with high sensitivity and specificity [9]. The object of the current report was to compare the diagnostic TelHashomer and pediatric criteria and to evaluate the importance of the Eurofever/PRINTO classification criteria in our pediatric FMF patients.

\section{Materials And Methods}

A total of 113 patients diagnosed with FMF according to clinical expert opinion and genetically confirmed in our pediatric nephrology department between November 2005-November 2018 were reviewed. The patients' files were examined retrospectively in terms of demographic and clinical features. Our control group included 117 patients without FMF who presented to our clinic with FMF symptoms such as recurrent fever, recurrent abdominal pain, recurrent joint pain, and chest pain. Demographic, clinical and genetic data were evaluated retrospectively. Mutation analyses in the MEFV gene were conducted with the reverse hybridization method of the most frequent 12 mutations of exon 2, 3, 5 and 10. Patients with FMF mutations were involved in the study. The patient and control groups were examined according to the Tel-Hashomer criteria [6] (the most widely used FMF criteria in adults), pediatric criteria [8], and the new Eurofever/PRINTO classification criteria [9] (Table I). The study was reviewed and approved by our institutional review board.

Statistical analyses were performed using Statistical Package for the Social Sciences (SPSS) for Windows, Version 18.0 (IBM SPSS Inc. Chicago, USA). $P$ values of $<0.05$ were considered as significant. Student's t-test and chi-square test were used to analyze continuous and categorical variables, respectively. Categorical variables were compared using the chi-square test. The sensitivity, specificity, positive predictive values (PPV), negative predictive values (NPV) and accuracy of the Tel-Hashomer [6], pediatric [8] and Eurofever/PRINTO [9] criteria were calculated based on $2 \times 2$ crosstabs.

\section{Results}

The demographic, clinical, laboratory and genetic data of the study group are shown in Table II. The patient group consisted of 113 FMF cases (51 male and 62 female). A family history of FMF was present in 57 patients (50.4\%). Consanguinity was described in 29 FMF patients $(25.6 \%)$. The mean age at disease onset was $6.78 \pm 4.64$ years (range, $2.3-11.6$ ), and the mean age at diagnosis was $8.59 \pm 4.57$ 
years (range, 4.1-13.3). The mean delay in diagnosis was 1.8 years. All the patients responded to colchicine treatment.

The control group $(n=117)$ contained patients without FMF who had clinical symptoms mimicking that of FMF, such as recurrent abdominal pain, fever, joint pain, and chest pain. Their MEFV gene analysis was negative. In the control group, a family history of FMF was reported in 27 individuals (20.5\%), and consanguinity was present in 24 patients with FMF (20.5\%). The control subjects' diagnoses were as follows: Periodic Fever, Aphthous Stomatitis, Pharyngitis, Adenitis Syndrome (PFAPA, $n=23$ ), recurrent abdominal pain unknown etiology $(n=18)$, juvenile idiopathic arthritis $(n=17)$, Helicobacter pylori gastritis $(n=15)$, inflammatory bowel disease $(n=10)$, reactive arthritis $(n=10)$, vasculitis $(n=8)$, recurrent pericarditis $(n=5)$, acute rheumatic fever $(n=3)$, Cryopyrin-associated periodic syndrome (CAPS, $n=3)$, Behcet's disease $(n=2)$, Hyperimmunoglobulin D Syndrome (HIDS, $n=2)$ and chronic recurrent multiple osteomyelitis $(n=1)$.

The distribution of the MEFV mutations in our patients was as follows: Seventy-seven patients (57\%) had two mutations in the MEFV gene, 31 were homozygous (M694V, $n=27)$ and 46 were compound heterozygous, and 36 patients (26.7\%) were heterozygous (24 had M694V, six had E148Q, five had M680I, and one had V726A). Clinical symptoms did not significantly differ according to genotypes $(p<0.05)$. The FMF patients were categorized into three groups according their mutations: 31 (26.5\%) patients with homozygous mutations, 46 (39.3\%) patients with compound heterozygous mutations, and 36 (30.8\%) patients with heterozygous mutations. When we compared these three groups according the three diagnostic criteria (pediatric, Tel-Hashomer, and Eurofever/PRINTO) we found the Eurofever/PRINTO classification criteria and pediatric criteria to have similar sensitivity values while the Tel-Hashomer criteria had higher sensitivity in patients with homozygous mutations (Table III).

The sensitivity and specificity of Tel-Hashomer criteria were determined as $69.9 \%$ and $95.7 \%$, respectively. The sensitivity of the pediatric criteria using at least two criteria was $88.6 \%$, and its specificity was 84.62\%. The Eurofever/PRINTO classification criteria displayed high sensitivity (93.8\%) and specificity (90.6\%) (Table IV). The positive predictive value (PPV) and the negative predictive value (NPV) were similar between pediatric criteria (84.75\%, 88.39\%) and Eurofever/Printo classification criteria $(90.6 \%$, $93.81 \%$ ) in our series. The Eurofever/PRINTO classification contains two sets of criteria: only clinical findings without the presence of confirmatory MEFV genotype and clinical findings with the presence of the confirmatory MEFV genotype. This classification had high sensitivity and specificity in our patients with FMF mutations.

\section{Discussion}

The diagnosis of FMF is established on clinical findings and supported by genetic testing. There are several sets of criteria established for the diagnosis of FMF, with the Tel-Hashomer criteria being the most common used [6]. Although the Tel-Hashomer criteria were determined for adults, they are also used successfully in the diagnosis of pediatric patients. However, difficulties in expressing the severity and 
location of pain and determining the level of fever (axillary, rectal, etc.) complicate the use of TelHashomer criteria in children. This reveals the necessity to identify more simple and practical diagnostic methods specific to children. In recent studies, the value and benefit of the Tel-Hashomer criteria in children have been investigated, and some new pediatric diagnostic sets of criteria have been described $[3,8,10-12]$.

The pediatric criteria for the FMF diagnosis were established by Yalcınkaya et al. [8] in a 2009 study including Turkish pediatric patients. In that study, five diagnostic criteria were defined as recurrent fever, abdominal pain, arthritis, chest pain, and a family history of FMF. Their control group consisted of consecutive patients without FMF who had clinical features mimicking that of FMF, similar to our study. They compared their results to those of the Tel-Hashomer criteria and determined the sensitivity and specificity of diagnosis as $88.7 \%$ and $92.6 \%$ in patients meeting at least two of their five criteria (Table V). However, they stated that the results of this study should also be valid in different ethnic groups and populations. Our study revealed similar sensitivity (88.6\%) and lower specifity (84.6\%) compared to Yalcınkaya et al. [8].

There were three previous attempts to validate the pediatric criteria. Kondi et al. [10] evaluated 70\% Sephardic Jews in an FMF group of patients in 2010 but they determined that the pediatric criteria did not make any further influence to the FMF diagnosis with compared to the Tel-Hashomer criteria and suggested the use of at least three of the Turkish pediatric criteria increased sensitivity to $77 \%$ and specifity to $95 \%$ (Table V). Demirkaya et al. [3] analyzed the largest number of pediatric patients with periodic fevers and with a various geographical and ethnic distribution in 2015. They showed that the pediatric criteria can be evaluated for the diagnosis of FMF, but it had higher sensitivity (87.4\%) and lower specificity (40.7\%), whereas the Tel-Hashomer criteria had lower sensitivity (45\%) and higher specificity (97.2\%). But Sag et al. [11] also evaluated pediatric criteria had higher sensitivity (93.4\%) and lower specificity (84.1\%), whereas the Tel-Hashomer criteria had lower sensitivity (88.7\%) but higher specificity $(92.6 \%)$ (Table V). We found using at least two of the pediatric criteria had $88.6 \%$ sensitivity and $84.6 \%$ specificity, which is consistent with the results presented by Yalcınkaya et al. [8] In contrast, we determined the specificity of the Tel-Hashomer criteria to be higher at $95.7 \%$. The main reason for this difference may be that as the reference diagnostic criteria, we used the Tel-Hashomer criteria whereas Yalcınkaya et al. [8] used the Livneh criteria that are more detailed and comprehensive [7]. However, the Livneh criteria can be more difficult to evaluate, especially in children. Therefore, using Yalcınkaya et al.'s criteria instead of the Livneh criteria may be simpler and more useful. We evaluated that the presence of at least two of the pediatric criteria were related to higher sensitivity $(88.6 \%)$ than the Tel-Hashomer criteria (69.9\%), confirming the findings of Yalcınkaya et al. [8] (86.5\%), Demirkaya et al. [3] (87.4\%)., and Sag et al. [11] (93.4\%). but lower compared to Kondi et al. (100\%). Contrary to the study of Kondi et al. [10], our study group consisted of Turkish patients with a homogeneous ethnic and geographical origin. The 2005 Turkish FMF study group revealed that $7.5 \%$ of FMF patients presented without fever, and this rate was higher than reported for the Jews, Arabs and Armenians [13]. Kondi et al. [10], Demirkaya et al. [3] and Sag et al. [11] formed their control groups with patients with periodic fever syndromes or autoinflammatory disease. In contrast, similar to the study of Yalcınkaya et al [8], our control group was 
not limited to patients with periodic fever syndromes and autoinflammatory disease, and it represented a wide and heterogeneous population with a wide range of symptoms mimicking FMF, such as recurrent abdominal pain, fever, joint pain, and chest pain. The rates of a family history of FMF $(20.5 \%)$ and consanguinity (20.5\%) were high in our control group. Although the frequency of FMF in Turkish population is high, the sensitivity of pediatric criteria has been reported to be higher in other countries where FMF is rarely seen [10].

Similar to Kondi et al. [10], our results showed that the patients with mutations in two alleles and those with one allele had similar clinical characteristics, and genetic status had no effect on clinical findings. We also evaluated the new Eurofever/PRINTO classification criteria in our FMF group and found them to be sensitive and specific for the classification of FMF (Table III, IV). However, research suggests that these classification criteria simplify the identification of FMF in clinical, epidemiological and translational studies but cannot be used for routine diagnostic purposes in individual patients $[9,14]$. Tanatar et al. investigated the Tel-Hashomer, Livneh, pediatric criteria and Eurofever/PRINTO criteria and found lower performance in both of four criteria in diagnosing and classifying heterozygous FMF patients [12]. Sag et al. [11] also compared the Tel-Hashomer, pediatric and Eurofever/PRINTO criteria and found that the Eurofever/PRINTO criteria reached the highest sensitivity in biallelic mutation patients.

Our results confirm that the Eurofever/PRINTO classification criteria can be successfully used in the diagnosis of FMF due to their high sensitivity and specificity, as also suggested by the authors that developed this tool. In our evaluation of the pediatric criteria, we determined that the presence of at least two of these criteria was adequate for a diagnosis of FMF in children. Thus, our study supports both the use of pediatric criteria and Eurofever/PRINTO classification criteria in clinical practice.

\section{Abbreviations}

CAPS: Cryopyrin-associated periodic syndrome

FMF: Familial Mediterranean fever

HIDS: Hyperimmunoglobulin D Syndrome

NPV: negative predictive values

PFAPA: Periodic Fever, Aphthous Stomatitis, Pharyngitis, Adenitis Syndrome

PPV: positive predictive values

SPSS: Statistical Package for the Social Sciences

\section{Declarations}

Funding: Authors declare that there has been no financial support for this work. 
Conflict of Interest: The authors declare that they have no conflict of interest.

Availability of data and material: Data are available on request from the authors.

Code availability: N/A

Authors' contributions: The lead author is Esra Nagehan Akyol Onder. Author Esra Nagehan Akyol Onder contributed to researching data for the article, the authors Esra Nagehan Akyol Onder and Esra Baskin contributed to discussion of its content, writing and reviewing, authors Kudret Ebru Ozcan and Kaan Savas Gulleroglu contributed to editing of the manuscript before submission. Author Feride Iffet Sahin performed the genetic analyzes of the patients.

Ethics approval: Local ethics committee approval was obtained.

Consent to participate: Written consent was obtained from all participants to participate in the study.

Consent for publication: Written consent was obtained from all paticipants for publication of the study.

\section{References}

1. Pras E, Livneh A, Balow JE Jr, Pras E, Kastner DL, Pras M, Langevitz P (1998) Clinical differences between North African and Iraqi Jews with familial Mediterranean fever. Am J Med Genet 13;75:216219 https://doi.org/10.1002/(sici)1096-8628(19980113)75:2<216::aid-ajmg20>3.0.co;2-r

2. Lidar M, Livneh A (2007) Familial Mediterranean fever: clinical, molecular and management advancements. Neth J Med 65: 318-324

3. Demirkaya E, Saglam C, Turker T, et al (2016) Paediatric Rheumatology International Trials Organisations (PRINTO); Eurofever Project. Performance of Different Diagnostic Criteria for Familial Mediterranean Fever in Children with Periodic Fevers: Results from a Multicenter International Registry. J Rheumatol 43: 154-160 https://doi.org/10.3899/jrheum.141249

4. Moradian MM, Sarkisian T, Ajrapetyan H, Avanesian N (2010) Genotype-phenotype studies in a large cohort of Armenian patients with familial Mediterranean fever suggest clinical disease with heterozygous MEFV mutations. J Hum Genet. 55: 389-393. https://doi.org/10.1038/jpg.2010.52

5. Ozçakar ZB, Yalçınkaya F, Cakar N, Acar B, Bilgiç AE, Uncu N, Kara N, Ekim M, Kasapçopur O (2011) Application of the new pediatric criteria and Tel Hashomer criteria in heterozygous patients with clinical features of FMF. Eur J Pediatr. 170:1055-1057. https://doi.org/10.1007/s00431-011-1404-y.

6. Sohar E, Gafni J, Pras M, Heller H (1967) Familial Mediterranean fever. A survey of 470 cases and review of the literature. Am J Med 43:227-253. https://doi.org/10.1016/0002-9343(67)90167-2.

7. Livneh A, Langevitz P, Zemer D, Zaks N, Kees S, Lidar T, Migdal A, Padeh S, Pras M (1997) Criteria for the diagnosis of familial Mediterranean fever. Arthritis Rheum. 1997 Oct;40:1879-1885. https://doi.org/10.1002/art.1780401023 
8. Yalçinkaya F, Ozen S, Ozçakar ZB, et al (2019) A new set of criteria for the diagnosis of familial Mediterranean fever in childhood. Rheumatology (Oxford) 48: 395-398. https://doi.org/ 10.1093/rheumatology/ken509

9. Gattorno M, Hofer M, Federici S, et al (2019) Eurofever Registry and the Paediatric Rheumatology International Trials Organisation (PRINTO). Classification Criteria for Autoinflammatory recurrent fevers. 78: 1025-1032. https://doi.org/ 10.1136/annrheumdis-2019-215048

10. Kondi A, Hentgen V, Piram M, Letierce A, Guillaume-Czitrom S, Koné-Paut I (2010) Validation of the new paediatric criteria for the diagnosis of familial Mediterrian fever: Data from a mixed population of 100 children from the French reference centre for auto-inflammatory disorders. Rheumatology (Oxford) 49: 2200-2203. https://doi.org/ 10.1093/rheumatology/keq252

11. Sag E, Demirel D, Demir S, et al (2020) Performance of the new 'Eurofever/PRINTO classification criteria' in FMF patients. Semin Arthritis Rheum 50: 172-175. 10.1016/j.semarthrit.2019.08.004

12. Tanatar A, Sönmez HE, Karadağ ŞE, et al (2020) Performance of Tel-Hashomer, Livneh, pediatric and new Eurofever/PRINTO classification criteria for familial Mediterranean fever. Rheumatol Int 40: $21-$ 27. https://doi.org/10.1007/s00296-019-04463-w

13. Tunca M, Akar S, Onen F, et al (2005) Turkish FMF Study Group. Familial Mediterranean fever (FMF) in Turkey: results of a nationwide multicenter study. Medicine (Baltimore) 84: 1-11. https://doi.org/10.1097/01.md.0000152370.84628.0c

14. Aletaha D, Neogi T, Silman AJ, et al (2010) Rheumatoid arthritis classification criteria: an American College of Rheumatology/European League Against Rheumatism collaborative initiative. Arthritis Rheum 62: 2569-2581. https://doi.org/ 10.1002/art.27584

\section{Tables}

Table I. The Tel-Hashomer, Pediatric and Eurofever/PRINTO Criteria 


\begin{tabular}{|c|c|c|c|}
\hline $\begin{array}{l}\text { Tel-Hashomer criteria } \\
\text { ( } \geq 2 \text { major or } 1 \text { major+2 } \\
\text { minor criteria) }\end{array}$ & $\begin{array}{l}\text { Pediatric criteria } \\
(\geq 2 \text { criteria) }\end{array}$ & $\begin{array}{l}\text { Eurofever/PRINTO } \\
\text { clinical-only } \\
\text { criteria }\end{array}$ & $\begin{array}{l}\text { Eurofever/PRINTO clinical } \\
+ \text { genetic criteria }\end{array}$ \\
\hline Major criteria & & Presence of & $\begin{array}{l}\text { Presence of the } \\
\text { confirmatory MEFV } \\
\text { genotype and at least one } \\
\text { of the following }\end{array}$ \\
\hline $\begin{array}{l}\text { 1- Recurrent febrile } \\
\text { episodes with serositis } \\
\text { (peritonitis, synovitis, and } \\
\text { pleuritis) }\end{array}$ & $\begin{array}{l}\text { 1- Fever (axillary } \\
\text { temperature of } \\
>38^{\circ} \mathrm{C}, 6-72 \mathrm{~h}, \geq 3 \\
\text { attacks) }\end{array}$ & $\begin{array}{l}\text { 1- Eastern } \\
\text { Mediterranean } \\
\text { ethnicity }\end{array}$ & $\begin{array}{l}\text { 1- Episodes lasting 1-3 } \\
\text { days }\end{array}$ \\
\hline $\begin{array}{l}\text { 2- Amyloidosis of AA type } \\
\text { without a predisposing } \\
\text { disease }\end{array}$ & $\begin{array}{l}\text { 2- Abdominal pain } \\
\text { (6-72 } \mathrm{h} \text { duration, } \\
\geq 3 \text { attacks) }\end{array}$ & $\begin{array}{l}\text { 2- Episodes } \\
\text { lasting 1-3 days }\end{array}$ & 2- Arthritis \\
\hline $\begin{array}{l}\text { 3- Favorable response to } \\
\text { colchicine treatment }\end{array}$ & $\begin{array}{l}\text { 3- Chest pain }(6-2 \mathrm{~h} \\
\text { duration, } \geq 3 \\
\text { attacks) }\end{array}$ & 3- Arthritis & 3- Chest pain \\
\hline Minor criteria & $\begin{array}{l}\text { 4- Arthritis (6-72 h } \\
\text { duration, } \geq 3 \\
\text { attacks, } \\
\text { oligoarthritis) }\end{array}$ & 4- Chest pain & 4- Abdominal pain \\
\hline $\begin{array}{l}\text { 1- Recurrent febrile } \\
\text { episodes }\end{array}$ & $\begin{array}{l}\text { 5- Family history of } \\
\text { FMF }\end{array}$ & 5- Abdominal pain & OR \\
\hline $\begin{array}{l}2 \text { - FMF in a first-degree } \\
\text { relative }\end{array}$ & & Absence of & $\begin{array}{l}\text { Absence of the } \\
\text { confirmatory MEFV } \\
\text { genotype and presence of } \\
\text { at least two of the } \\
\text { following }\end{array}$ \\
\hline \multirow[t]{4}{*}{ 3- Erysipelas-like erythema } & & $\begin{array}{l}\text { 1- Aphthous } \\
\text { stomatitis }\end{array}$ & $\begin{array}{l}\text { 1- Episodes lasting 1-3 } \\
\text { days }\end{array}$ \\
\hline & & 2- Urticarial rash & 2- Arthritis \\
\hline & & $\begin{array}{l}\text { 3- Maculopapular } \\
\text { rash }\end{array}$ & 3- Chest pain \\
\hline & & $\begin{array}{l}\text { 4- Painful lymph } \\
\text { nodes }\end{array}$ & 4- Abdominal pain \\
\hline
\end{tabular}

Table II. Demographic Features of our Study Group 


\begin{tabular}{|c|c|c|c|}
\hline & FMF Group (n:113) & Control Group (n:117) & $p$ value \\
\hline Male/female & $51 / 62$ & $52 / 65$ & $>0.05$ \\
\hline Current age, mean $\pm S D$, years & $13.93 \pm 5.3$ & $12.93 \pm 4.54$ & $>0.05$ \\
\hline Age at onset, mean $\pm S D$, years & $6.78 \pm 4.64$ & $7.08 \pm 4.08$ & $>0.05$ \\
\hline Age at diagnosis mean $\pm S D$, years & $8.59 \pm 4.57$ & $8.52 \pm 3.82$ & $>0.05$ \\
\hline Consanguinity, n (\%) & $29(25.6 \%)$ & $24(20.5 \%)$ & $>0.05$ \\
\hline Fever, n (\%) & 79 (69.9\%) & $45(38.4 \%)$ & $<0.05$ \\
\hline Abdominal pain & $88(77.9 \%)$ & $30(25.6 \%)$ & $<0.05$ \\
\hline Chest pain, $\mathrm{n}(\%)$ & $32(28.3 \%)$ & $7(5.6 \%)$ & $<0.05$ \\
\hline Arthritis, n (\%) & $40(35.4 \%)$ & $27(23 \%)$ & $<0.05$ \\
\hline Family history of FMF, n (\%) & $57(50.4 \%)$ & $24(20.5 \%)$ & $<0.05$ \\
\hline $\mathrm{ESR} \uparrow$ (attack), n (\%) & $102(90.3 \%)$ & $28(23.9 \%)$ & $<0.05$ \\
\hline $\mathrm{CRP} \uparrow$ (attack), n (\%) & $101(89.4)$ & $31(26.5 \%)$ & $<0.05$ \\
\hline Proteinuria, n (\%) & $12(10.6 \%)$ & $1(0.85 \%)$ & $<0.05$ \\
\hline Vomiting, n (\%) & $6(5.3 \%)$ & $17(14.5 \%)$ & $>0.05$ \\
\hline Splenomegaly, n (\%) & $9(7.96 \%)$ & $0(0 \%)$ & $<0.05$ \\
\hline Myalgia, n (\%) & $20(17.7 \%)$ & $13(11.1 \%)$ & $>0.05$ \\
\hline
\end{tabular}

$\uparrow$ indicates increased, ESR: erythrocyte sedimentation rate, CRP: C-reactive protein

Table III. Sensitivity of the Pediatric Criteria Compared with the Tel-Hashomer and Eurofever/PRINTO Criteria in Homozygous, Compound Heterozygous and Heterozygous Patients

\begin{tabular}{|lllll|}
\hline & $\begin{array}{l}\text { Homozygous } \\
(\mathbf{n = 3 1 )}(\%)\end{array}$ & $\begin{array}{l}\text { Compound heterozygous } \\
(\mathbf{n = 4 6 )}(\%)\end{array}$ & $\begin{array}{l}\text { Heterozygous } \\
(\mathbf{n = 3 6 )}(\%)\end{array}$ & $P$ value \\
\hline$\geq 2$ pediatric criteria & $27(87 \%)$ & $40(86.9 \%)$ & $33(91.7 \%)$ & $>0.05$ \\
\hline$\geq 3$ pediatric criteria & $20(64.5 \%)$ & $21(45.6 \%)$ & $16(44.4 \%)$ & $>0.05$ \\
\hline Tel-Hashomer criteria & $25(80.6 \%)$ & $31(67.4 \%)$ & $23(63.9 \%)$ & $>0.05$ \\
\hline Eurofever/PRINTO criteria & $31(100 \%)$ & $40(86.9 \%)$ & $35(97.2 \%)$ & $<0.05$ \\
\hline
\end{tabular}

Table IV. Sensitivity, Specificity, PPV, NPV of the Pediatric Criteria Compared with the Tel-Hashomer and Eurofever/PRINTO Criteria 


\begin{tabular}{|c|c|c|c|c|}
\hline & $\begin{array}{l}\text { Sensitivity } \\
(95 \% \mathrm{Cl})\end{array}$ & $\begin{array}{l}\text { Specificity } \\
(95 \% \mathrm{Cl})\end{array}$ & $\begin{array}{l}\text { PPV } \\
(95 \% \mathrm{Cl})\end{array}$ & $\begin{array}{l}\text { NPV } \\
(95 \% \mathrm{Cl})\end{array}$ \\
\hline$\geq 2$ pediatric criteria & $\begin{array}{l}88.6(81.13- \\
93.73)\end{array}$ & $\begin{array}{l}84.62 \text { (76.78- } \\
90.62)\end{array}$ & $\begin{array}{l}84.75(78.32- \\
89.52)\end{array}$ & $\begin{array}{l}88.39(81.95 \\
92.74)\end{array}$ \\
\hline$\geq 3$ pediatric criteria & $\begin{array}{l}50.4(40.88- \\
59.98)\end{array}$ & $100(96.9-100)$ & 100 & $\begin{array}{l}67.63(63.43 \\
71.56)\end{array}$ \\
\hline$\geq 4$ pediatric criteria & $\begin{array}{l}18.6(11.89- \\
26.99)\end{array}$ & $100(96.9-100)$ & 100 & $\begin{array}{l}55.98(53.8- \\
58.14)\end{array}$ \\
\hline All pediatric criteria & $\begin{array}{l}4.42(1.45- \\
10.02)\end{array}$ & $100(96.9-100)$ & 100 & $\begin{array}{l}56.1(51.01- \\
52.99)\end{array}$ \\
\hline Tel-Hashomer criteria & $\begin{array}{l}69.9(60.57- \\
78.18)\end{array}$ & $\begin{array}{l}95.7(90.31 \text { - } \\
98.6)\end{array}$ & $\begin{array}{l}94.05(86.92- \\
97.41)\end{array}$ & $\begin{array}{l}76.71(71.27 \\
81.39)\end{array}$ \\
\hline $\begin{array}{l}\text { Eurofever/PRINTO } \\
\text { criteria }\end{array}$ & $\begin{array}{l}93.8(87.65- \\
97.47)\end{array}$ & $\begin{array}{l}90.6(83.8- \\
95.21)\end{array}$ & $\begin{array}{l}90.6(84.57- \\
94.43)\end{array}$ & $\begin{array}{l}93.81(88.06 \\
96.89)\end{array}$ \\
\hline
\end{tabular}

(Abbreviations: Cl, Confidence Interval; PPV, Positive predictive value; NPV, Negative predictive value)

Table V. Sensitivity, Specificity, PPV, NPV of the Pediatric, Tel-Hashomer and Eurofever/Printo Criteria in Different Case Series 


\begin{tabular}{|lllll|}
\hline Criteria & Sensitivity & Specificity & PPV & NPV \\
\hline Our series & & & & \\
\hline$\geq 2$ pediatric criteria & 88.6 & 84.62 & 84.75 & 88.39 \\
\hline$\geq 3$ pediatric criteria & 50.4 & 100 & 100 & 67.63 \\
\hline Tel-Hashomer criteria & 69.9 & 95.7 & 94.05 & 76.71 \\
\hline Eurofever/PRINTO criteria & 93.8 & 90.6 & 90.6 & 93.81 \\
\hline Yalcınkaya et al. ${ }^{7}$ & & & & \\
\hline$\geq 2$ pediatric criteria & 86.5 & 93.6 & 94.2 & 85.2 \\
\hline$\geq 3$ pediatric criteria & 55 & 99 & & \\
\hline Tel-Hashomer criteria & 98.8 & 54.6 & 72.4 & 97.5 \\
\hline Kondi et al. ${ }^{9}$ & & & & \\
\hline$\geq 2$ pediatric criteria & 100 & 50 & 83.3 & 100 \\
\hline$\geq 3$ pediatric criteria & 77 & 95 & 97.5 & 62.3 \\
\hline Tel-Hashomer criteria & 99 & 45 & 81.8 & 94.7 \\
\hline Demirkaya et al. ${ }^{3}$ & & & & \\
\hline$\geq 2$ pediatric criteria & 87.4 & 40.7 & 61.1 & 74.8 \\
\hline Tel-Hashomer criteria & 45 & 97.2 & 93.8 & 65 \\
\hline Eurofever/PRINTO criteria ${ }^{8}$ & 94 & 95 & & \\
\hline Sag et al. ${ }^{10}$ & & & & \\
\hline$\geq 2$ pediatric criteria & 93.4 & 84.1 & & \\
\hline Tel-Hashomer criteria & 88.7 & 92.6 & & \\
\hline
\end{tabular}

(Abbreviations: PPV: Positive predictive value, NPV: Negative predictive value) 